January 2022

\title{
A Pilot Interdisciplinary Falls Screening and Educational Event: Perceptions of Community-Dwelling Older Adults
}

\author{
Lisa J. Knecht-Sabres \\ Midwestern University, Iknech@midwestern.edu \\ Timothy A. Hanke \\ Midwestern University, THANKE@midwestern.edu \\ Michelle M. Lee \\ Midwestern University,mlee1x@midwestern.edu \\ Minetta Wallingford \\ Midwestern University, minettaw@gmail.com \\ Lisa Palmisano \\ Midwestern University, Ipalmi@midwestern.edu \\ See next page for additional authors
}

Follow this and additional works at: https://nsuworks.nova.edu/ijahsp

Part of the Medicine and Health Sciences Commons

\section{Recommended Citation \\ Knecht-Sabres LJ, Hanke TA, Lee MM, Wallingford M, Palmisano L, Elliott-Burke T, Huntington-Alfano K, Higgins S, Dillon T, Mazan J. A Pilot Interdisciplinary Falls Screening and Educational Event: Perceptions of Community-Dwelling Older Adults. The Internet Journal of Allied Health Sciences and Practice. 2022 Jan 10;20(1), Article 19.}

This Manuscript is brought to you for free and open access by the College of Health Care Sciences at NSUWorks. It has been accepted for inclusion in Internet Journal of Allied Health Sciences and Practice by an authorized editor of NSUWorks. For more information, please contact nsuworks@nova.edu. 


\title{
A Pilot Interdisciplinary Falls Screening and Educational Event: Perceptions of Community-Dwelling Older Adults
}

\begin{abstract}
Introduction: Falls are the leading cause of death and disability among people 65 years of age and older. Likewise, falls have psychological consequences which often lead to avoidance of activities, fear of falling, and further disabilities. Even though the impact of falls on one's daily life and independence are substantial, evidence suggests that falls can be prevented by multi-factorial assessments and clientspecific interventions. Objective: The purpose of this study was to determine (a) perceived knowledge of falls, (b) reported confidence in fall prevention, (c) perceived likelihood of implementing falls screening recommendations, (d) reported fear of falling, and (e) perceived value and satisfaction among communitydwelling older adults who attended an interdisciplinary falls screening and education event. Methods: An interdisciplinary group of professionals from behavioral sciences, family medicine, occupational therapy, optometry, pharmacy, and physical therapy screened 33 community dwelling older adult participants (66-84 years of age) using multi-factorial assessments and discipline-specific screening tools. Individualized recommendations were provided to each participant in verbal and written formats. Participants then completed a questionnaire at the conclusion of the event regarding their perceptions of knowledge gained about falls, confidence in preventing falls, perceived likelihood of implementing fall screening recommendations, fear of falling, and overall feedback regarding the event. Results: The majority of the participants indicated increased perceived knowledge of falls, confidence in preventing falls, and perceived high likelihood of implementing recommendations, along with decreased fear of falling. The majority of the participants also found the event to be valuable (85\%), enjoyable (94\%), and easy to understand (100\%). Conclusion: The results of this study suggest that participants found this falls screening event to be valuable and improved their knowledge regarding falls, as well as their confidence in being able to prevent falls. This study highlights the potential value of an interdisciplinary team approach to increase knowledge, enhance prevention, and decrease fear of falling in community dwelling older adults.
\end{abstract}

\section{Author Bio(s)}

Lisa Jean Knecht-Sabres, DHS, OTR/L, is a Professor in the Occupational Therapy Program at Midwestern University. Her clinical expertise has focused on enhancing occupational performance for older adults. She has published on topics related to older adults, experiential learning, interprofessional education, and enhancing readiness for clinical practice.

Timothy Hanke, PT, PhD, is a Professor at Midwestern University. His clinical experience has focused on geriatric and neurological physical therapy. Dr. Hanke has published on topics related to balance, falls, and mobility in older adults and in persons with stroke.

Michelle M. Lee, PhD, ABPP, is a Professor and Associate Program Director in the Department of Behavioral Sciences at Midwestern University. She is Board Certified in Clinical Psychology. Her clinical experience has focused on psychological issues in later life. She has co-authored several scholarly publications.

Minetta Wallingford, DrOT, OTR/L, is a retired Associate Professor from the Midwestern University Occupational Therapy program. She has extensive experience in teaching and coordinating fieldwork education for academic occupational therapy programs. She has presented and published nationally on topics related to clinical education, evidence-based practice, and geriatrics.

Lisa Palmisano, PharmD, BCACP, is an Associate Professor at Midwestern University. Her clinical expertise has focused on clinical pharmacy and interprofessional education. She served as the Medical Director of the COVID Vaccine Clinic. She is dedicated to the education and growth of students, patients, and healthcare providers. 
Teresa Elliott-Burke PT, DPT, MHS, WCS, is an Associate Professor and Academic Coordinator at Midwestern University. Dr. Elliott-Burke has more than 40 years of patient care and managerial experience in outpatient physical therapy. Her research interest is in pelvic girdle dysfunction, real-time ultrasound imaging and healthcare business issues.

Kimberly A. Huntington-Alfano, D.O. is a Clinical Associate Professor for the Chicago College of Osteopathic Medicine and Medical Director of the Multispecialty Clinics at Midwestern University. She is a board-certified family physician.

Susanne Higgins OTD, OTR/L, CHT is an Associate Professor of Occupational Therapy at Midwestern University and a Certified Hand Therapist. She volunteers for the Education Division of the American Society of Hand Therapists. She presents continuing education courses related to upper extremity rehabilitation.

Thomas Dillon, PT, DPT, OCS is Clinical Assistant Professor and at Midwestern University and provides physical therapy services at the Physical Therapy Institute at the Midwestern University Multispecialty Clinic. He is board certified in orthopedics.

Jennifer L. Mazan, Pharm.D. is an Associate Professor at Midwestern University. Her clinical experience focuses on clinical pharmacy. She also serves as the course director for several clinical skills courses. Her research interests include patient communication and education, and the scholarship of teaching and learning.

\section{Acknowledgements}

The authors would like to thank Midwestern University's College of Health Sciences Geriatric Research and Education Facilitation Grant for their support in this study.

\section{Authors}

Lisa J. Knecht-Sabres, Timothy A. Hanke, Michelle M. Lee, Minetta Wallingford, Lisa Palmisano, Teresa Elliott-Burke, Kim Huntington-Alfano, Susanne Higgins, Thomas Dillon, and Jennifer Mazan 


\title{
IJAHSP \\ The Internet Journal of Allied Health Sciences and Practice \\ Dedicated to allied health professional practice and education \\ Vol. 20 No. 1 ISSN 1540-580X
}

\section{A Pilot Interdisciplinary Falls Screening and Educational Event: Perceptions of Community-Dwelling Older Adults}

\author{
Lisa J. Knecht-Sabres \\ Timothy A. Hanke \\ Michelle M. Lee \\ Minetta Wallingford \\ Lisa Palmisano \\ Teresa Elliot-Burke \\ Kim Huntington-Alfano \\ Susanne Higgins \\ Thomas Dillon \\ Jennifer Mazan \\ Midwestern Univeristy \\ United States
}

\begin{abstract}
Introduction: Falls are the leading cause of death and disability among people 65 years of age and older. Likewise, falls have psychological consequences which often lead to avoidance of activities, fear of falling, and further disabilities. Even though the impact of falls on one's daily life and independence are substantial, evidence suggests that falls can be prevented by multi-factorial assessments and client-specific interventions. Objective: The purpose of this study was to determine (a) perceived knowledge of falls, (b) reported confidence in fall prevention, (c) perceived likelihood of implementing falls screening recommendations, (d) reported fear of falling, and (e) perceived value and satisfaction among community-dwelling older adults who attended an interdisciplinary falls screening and education event. Methods: An interdisciplinary group of professionals from behavioral sciences, family medicine, occupational therapy, optometry, pharmacy, and physical therapy screened 33 community dwelling older adult participants (66-84 years of age) using multi-factorial assessments and discipline-specific screening tools. Individualized recommendations were provided to each participant in verbal and written formats. Participants then completed a questionnaire at the conclusion of the event regarding their perceptions of knowledge gained about falls, confidence in preventing falls, perceived likelihood of implementing fall screening recommendations, fear of falling, and overall feedback regarding the event. Results: The majority of the participants indicated increased perceived knowledge of falls, confidence in preventing falls, and perceived high likelihood of implementing recommendations, along with decreased fear of falling. The majority of the participants also found the event to be valuable ( $85 \%)$, enjoyable $(94 \%)$, and easy to understand (100\%). Conclusion: The results of this study suggest that participants found this falls screening event to be valuable and improved their knowledge regarding falls, as well as their confidence in being able to prevent falls. This study highlights the potential value of an interdisciplinary team approach to increase knowledge, enhance prevention, and decrease fear of falling in community dwelling older adults.
\end{abstract}

Keywords: falls, older adults, interdisciplinary screening 


\section{INTRODUCTION}

Falls are the leading cause of death and disability among people 65 years of age and older. ${ }^{1}$ In 2016 , almost 30,000 residents of the United States aged 65 or older died as the result of a fall. ${ }^{2}$ In addition to the high fatality rate, approximately $25 \%$ of the falls in older adults caused a serious injury such as a broken bone or a head injury which led to a hospitalization stay for their injury.3,4 Unfortunately, approximately $30 \%$ of adults aged 65 years or older fall each year. ${ }^{3}$ Furthermore, two-thirds of those people aged 65 and older who fall will have another fall within one year. ${ }^{3}$ Moreover, the risk of falling increases with age, resulting in approximately $50 \%$ of adults aged 85 or older having at least one fall every year. ${ }^{3}$

Among community-dwelling older adults, falls are one of the most expensive medical conditions. In 2015, the total medical costs for falls totaled more than 50 billion dollars. ${ }^{5}$ Aside from the substantial socio-economic consequences of falls, the impact of falls on one's independence are substantial. 1,6 When not fatal, falls often lead to bone fractures, head injuries, and loss of independence in basic self-care, basic mobility, and instrumental activities of daily living such as housekeeping, shopping, and community mobility. 1,6,7,8 Falls also have psychological consequences such as fear of falling and activity avoidance which can result in further disabilities, complications, and dependence on others for daily activities. ${ }^{7,8} \mathrm{An}$ older adult's perspective of falls and their fear of falling are also noted to contribute to confidence in self-management of falls. ${ }^{9}$ Thus, assessing changes in fear or confidence in self-management of falls throughout prevention and management processes is prudent.

Even though falls are typically multifactorial in nature, there is evidence to suggest that they can be prevented by screenings and implementation of client-specific interventions. ${ }^{10,11,16}$ Some of the major intrinsic risk factors for falls in community-dwelling older adults include advancing age, a previous fall, functional limitations in balance and mobility, visual impairment, urinary incontinence, polypharmacy and/or benzodiazepine use, chronic disease such as cardiac and neurological disease, low body mass index, cognitive impairment, depression, anxiety, and impairments in activities of daily living.,7,11-15 Some of the major extrinsic risk factors include things such as improper use of assistive devices, obstacles, loose carpeting, poor lighting, and slippery surfaces.,11 These intrinsic and extrinsic risk factors emphasize the need for collaboration among health care professionals and the need for comprehensive home and environmental assessments, as well as safety education. ${ }^{11,16,17}$

Due to the extensive impact that falls have on one's health, independence, and the economy, it is imperative that experts in their respective healthcare disciplines identify how falls (and fall risk) can be better prevented, assessed, and treated. There is evidence that falls can be prevented by screening to detect risk factors and by the prescription of tailored interventions. ${ }^{10,11,16}$ Organizations such as the Centers for Disease Control (CDC) and Prevention's Stopping Elderly Accidents, Deaths \& Injuries (STEADI), National Institute for Health and Care Excellence (NICE), the United States Preventive Task Force (USPSTF), and American Geriatrics Society/British Geriatrics Societies (AGS/BGS) have provided practice guidelines for the assessment and prevention of falls in community-dwelling older adults for health care practitioners. ${ }^{6,18-20}$ Because of the devastating consequences of falls, prevention is at the core of health care reform initiatives that are being developed and implemented. To prevent falls, the AGS/BGS Guidelines state that: (1) all older adults should be screened for fall risk; (2) multi-factorial assessments targeting an individual's risk factors should be conducted on those who screen positive for risk of falling; and (3) tailored interventions should be implemented to address identified risk factors. ${ }^{20}$ Such an approach requires an interdisciplinary team of professionals committed to assisting community-dwelling older adults through this process. To promote access to falls prevention programming, the National Council on Aging (NCOA) has established the first day of fall as Falls Prevention Awareness Day (FPAD). Thus, the purpose of this pilot project was to support these initiatives by developing and implementing an interdisciplinary, evidence-based, falls screening and educational event for older adults living in the local community. Since there does not appear to be any research which has investigated the older adults' perceived value of interdisciplinary falls screening and educational events, the specific aim of this study was to investigate the participants' perceptions regarding an interdisciplinary falls screening and educational event and to examine their (a) perceived knowledge of falls, (b) reported confidence in fall prevention, (c) perceived likelihood of implementing falls screening recommendations, and (d) reported fear of falling among event attendees after attending this event.

\section{METHODS}

\section{Description of the Falls Screening Process}

This interdisciplinary Falls Screening and Educational Event was offered to community dwelling older adults in the Chicagoland area. Professionals from behavioral sciences, family medicine, occupational therapy, optometry, pharmacy, and physical therapy screened participants using discipline-specific screening tools. Individualized recommendations were provided to each participant in verbal and written formats. This event was held at the University's Multispecialty Healthcare Clinic which provided an environment in which the professionals from six different disciplines were able to rotate into different clinical rooms, allowing the participants $(n=33)$ to stay in the same location throughout the screening process. The healthcare professionals involved in the screening aspects of this event consisted of both academic and clinical faculty associated with the university and multidisciplinary 
clinic. Student volunteers from each of the above listed disciplines were also involved in this event to help ensure that the event ran smoothly. This study used data from two different falls screening events. The first falls screening event occurred in October of 2018 and the second falls screening event occurred in October of 2019. The falls screening event planned for 2020 was cancelled due to the pandemic. The falls screening process entailed that each participant met individually with each member of the interdisciplinary team for approximately 10-15 minutes for a discipline-specific assessment and participant-centered recommendations. At the end of the Falls Screening and Educational Event, participants were asked to complete a brief demographic sheet and a survey to assess the perceived value and satisfaction with the falls screening process. Each participant was present for approximately 2 hours, which included checking- in, the interdisciplinary screenings and educational processes, and the post-event survey.

\section{Participants}

Community-dwelling older adults aged 65 years and older in the Chicagoland area were eligible to attend this free event. Recruitment of participants was elicited via the placement of advertisement flyers at local community senior centers, libraries, churches, and clinics. Participants were also recruited through announcements on the University's Multispecialty Clinic's webpage and via word of mouth and snowball sampling. A total of 33 community dwelling older adults participated in this study. Twenty-four older adults participated in this event on the first date and nine older adults participated in this event on the second date. All participants drove themselves or found their own transportation to the event and provided informed consent to participate in this study. Participants were between the ages of 66-84 with a mean age of 73.3 years $(S D=6.71)$. A majority of the participants were female (72.8\%, $n=24)$. Most were Caucasian (81.8\%, $n=27)$, with 12.2\% African American $(n=4), 3 \%$ Pakistani $(n=1)$ and 3\% Asian American $(n=1)$. Approximately $85 \%$ of the participants completed education beyond high school with $42.4 \%$ of the participants completing college $(n=14) ; 30.3 \%$ post-graduate college $(n=10) ; 12.1 \%$ trade/business school $(n=4)$; and $12.1 \%$ high school/GED $(n=4)$. One participant declined to answer the question regarding educational level, even though options were provided for completed $8^{\text {th }}$ grade and completed less than $8^{\text {th }}$ grade education. Approximately half were married $(54.5 \%, n=18) ; 18.2 \%$ were single $(n=6) ; 15.2 \%$ were divorced or separated $(n=5)$, and $12.1 \%$ were widowed $(n=4)$. A large majority of the participants $(84.8 \%$, $n=28$ ) answered "Yes" to the question "Have you ever fallen before?" All participants lived independently in the community.

\section{Discipline Specific Screening Tools and Interventions Behavioral Sciences}

The Behavioral Sciences team consisted of two licensed clinical psychologists. They screened the participants on three domains: (1) cognitive impairment; (2) depression; and (3) anxiety, as these three factors have been identified as risk factors for falls in older adults. ${ }^{21}$ Specifically, the team used the Mini-Mental State Exam, the Geriatric Depression Scale-Short Form (GDS-SF), and the Geriatric Anxiety Inventory-Short Form (GAI-SF) respectively. ${ }^{22-24}$ These measures were selected due to their desired brevity, the fact that they were developed specifically for older adults, their past use as part of falls prevention research with older adults, and/or their desirable psychometric properties. ${ }^{22-26}$ If the participant screened positive for signs of cognitive impairment, depressive symptoms, or anxiety symptoms, the Behavioral Sciences team informed the participant both verbally and in writing and suggested that he/she follow-up with his/her primary healthcare provider for further evaluation. A brief handout was provided to all participants describing the risks of cognitive impairment, depression, and anxiety for falls in older adults and resources for further information in terms of managing these risks.

\section{Family Medicine}

The Family Medicine team included one licensed Doctor of Osteopathic Medicine, a Medical Assistant, and two $3^{\text {rd }}$ year and two $4^{\text {th }}$ year medical students. The medical students used the protocol for Measuring Orthostatic Blood Pressure to screen for postural hypotension under the direct supervision of the medical assistant or doctor. ${ }^{6}$ That is, blood pressure and pulse were checked in the supine and standing positions and were recorded on the participant's screening form. Participants were provided the results of this screening test. Any participant with abnormal results was provided with the brochure Postural Hypotension: What it is \& How to Manage it and referred to his/her personal physician for further evaluation and treatment. ${ }^{6}$ Additionally, the Family Medicine team utilized the National Stroke Association's FAST test to teach older adults the sudden warning signs of stroke and reminded them to immediately seek medical attention if these symptoms develop in themselves or loved ones. ${ }^{27}$ The National Stroke Association's FAST wallet card was provided to all participants as a quick reminder to act fast if signs of stroke develop.

\section{Occupational Therapy}

The occupational therapy team which consisted of three registered and licensed occupational therapists with an expertise in geriatrics and/or falls prevention. The occupational therapy team asked the participants to fill out the Home Safety Self-Assessment Tool (HSSAT) before the event. ${ }^{28-30}$ The HSSAT is a reliable and valid instrument used to identify fall risks in the home environment 
and has been found to be an effective educational tool to help improve safety in the home. ${ }^{28,29}$ Participants were also asked to fill out and turn in their responses to a researcher-developed questionnaire prior to attending the interdisciplinary falls screening and educational event. This researcher-developed questionnaire was informed by the literature and expert opinion. It contained eight general questions regarding the participant's history of falls, location and circumstances related to previous falls, history of near falls/stumbling, feelings of light-headedness/dizziness, fear of falling, and limitations of daily activities/occupations due to falls or fear of falling (important pieces of information not contained in the HSSAT).

The occupational therapy team discussed and reviewed the data from the above-mentioned screening tools with the participant during the interdisciplinary falls screening event. While reviewing the data, the occupational therapy team often probed further regarding potential environmental and occupational concerns related to fall risk. Client-specific recommendations to reduce fall risk in the home and community were made in both verbal and written formats. These included but were not limited to the following recommendations: installation of adaptive equipment (e.g., grab bars in the shower/bathtub, shower chair, bathtub transfer bench); implementation of home modifications (e.g., railings by stairs, increased lighting, removal of clutter on the floor); and/or modifications to daily occupations (e.g., laundry) to enhance safety and to decrease fall risk. If suggestions were made for installation of adaptive equipment or home modifications, participants were provided with information on where they could purchase the suggested items. The participant was also encouraged to discuss and share written findings from this event with his/her primary care physician.

\section{Optometry}

The optometry team which consisted of two licensed optometrists screened for deficits with visual acuity via the use of the Snellen letter, high contrast chart, contrast sensitivity with the use of the Pelli-Robson, low contrast chart, and visual fields via the use of Confrontation and Amsler grid screenings. ${ }^{31}$ The optometry team made recommendations for an additional comprehensive eye examination by an eye care physician based on the results of the screening, or if it had been greater than one year since the participant's last comprehensive eye examination. The optometry team also provided a handout to the participant which included the vision screening test results to take to their eye care physician, as well as recommendations on ways to maximize their vision to reduce the risk of falls.

\section{Pharmacy}

The pharmacy team which consisted of two licensed pharmacists asked the participants to provide a current list of medications prior to the Falls Screening and Education Event. The medication list was reviewed, and potentially inappropriate medications (PIMs) were screened using the American Geriatrics Society 2015 updated Beers criteria for PIM use in older adults. ${ }^{32}$ On the day of the event, the medication list that was received by the pharmacy team prior to the event date was reviewed with the participant to assure accuracy of the medication list. If the medication list was modified by the participant, the pharmacy team reviewed the updated medication list with PIMs in the Beers Criteria. ${ }^{32}$

The pharmacy team generated a summary sheet of the PIMs and discussed the concerns/findings with participant, as well as answers to any questions related to the PIMs. The summary sheet, Beers Criteria, and Screening Tool of Older People's Prescriptions (STOPP)/Screening Tool to Alert to Right Treatment (START) criteria were put into the participant's folder, and the participant was encouraged to bring their PIMs summary sheet and discuss the findings with his/her primary care physician. ${ }^{33}$

\section{Physical Therapy}

The physical therapy team which consisted of two licensed physical therapists with expertise in falls prevention used the CDC STEADI Toolkit to screen for falls within the past year, as well as physical performance measures for balance, mobility, and lower extremity strength.34-37 The Questionnaire for Urinary Incontinence Diagnosis (QUID) was added to screen for urinary incontinence. ${ }^{38}$ Falls efficacy was assessed using the Modified Falls Efficacy Scale. ${ }^{39}$ The physical therapy team reviewed the findings with the participants, made recommendations for additional examination and interventions based on the results of the screening, and encouraged the participants to share the summary of written findings and recommendations with his/her primary care physician. Physical therapy recommendations were in the form of community or individualized exercise programs focusing on things such as balance training, strengthening exercises, and/or functional mobility training.

\section{Interdisciplinary Healthcare Students}

To promote interdisciplinary experiences among future healthcare providers in working with older adults, approximately 15 student volunteers also assisted with this event. Student volunteers performed a myriad of jobs, including but not limited to helping keep track of time, alerting specialists when it was time to switch rooms, assisting participants with checking-in, bringing

(c) The Internet Journal of Allied Health Sciences and Practice, 2022 
participants to their assigned rooms, helping with documentation, etc. Volunteer students from behavioral sciences, occupational therapy, optometry, osteopathic medicine, pharmacy, and physical therapy were recruited via an e-mail which described the interdisciplinary falls screening event and included an invitation to participate in this event. Participation was strictly on a volunteer basis and student participants were registered on a first-come, first-serve basis.

\section{Data Collection and Analysis}

Following the screening process, participants were invited to complete a brief demographic sheet, a feedback questionnaire, and a researcher-developed survey to assess their (a) perceived knowledge of falls, (b) reported confidence in fall prevention, (c) perceived likelihood of implementing falls screening recommendations, and (d) reported fear of falling. Participants were given an opportunity to ask questions regarding the study. Neither the demographic sheet nor falls screening surveys contained any identifiable personal information. This study was approved by the Midwestern University's Institutional Review Board

A demographic form was used to collect data about the participants' age, gender, race, education, marital status, past fall history, and type of residential setting. The survey (Appendix A) contained four questions asking participants to rate how much they felt their knowledge and confidence in preventing falls improved, fear of falling decreased, as well as their likelihood of implementing recommendations after attending the falls screening event. Participants were asked to respond to each of these questions using an 11-point Likert scale $(0=$ Not at all; $10=$ Completely). In addition, the participants were asked to fill out a feedback form (Appendix B) which contained four closed ended questions and three open ended questions regarding the event. The four closed ended questions asked participants to rate how valuable, enjoyable, and informative they felt the falls screening event was, as well as how comfortable they felt completing the screenings with the interdisciplinary team. Participants responded to each of these four questions on a 5-point scale (1=Not at All; 2=Somewhat; 3=Moderately; 4= Very; and 5=Extremely). The three open ended questions inquired about what they liked best about the falls screening event, suggestions for improving the event, and ideas regarding the offering of any other events related to the health of older adults.

All data was entered into an Excel spreadsheet. Descriptive statistics (mean, SD, and percentages) were used to analyze demographic data, data regarding participants' perceived impact of the Falls Screening and Educational Event on fall prevention, as well as the participants' feedback regarding the effectiveness of the Falls Screening and Educational Event. Thematic analysis was also used to analyze qualitative data. ${ }^{42}$ Thematic data analysis is a qualitative approach which identifies patterns and similar themes across participants allowing meaning to emerge from the raw data. The first author immersed herself in the data by "repeated reading" as a way to gain familiarity and to begin to find patterns. Next, this researcher generated initial codes from the data and collaborated with several of the authors/researchers until consensus was reached regarding both codes and themes. Trustworthiness of data was enhanced through peer review, as well triangulation of data via a mixed-methods design.

\section{RESULTS}

Results indicated that participants felt that the Falls Screening and Educational Event, on average: (1) greatly improved their knowledge of falls ( mean $=8.00, S D=1.82$, range $=3-10)$; (2) greatly improved their confidence in their own ability to prevent falls ( mean $=8.24, S D=1.68$, range $=3-10)$; (3) moderately decreased their fear of falling (mean = 6.81, $S D=2.85$, range = 1-10); and (4) were highly likely to implement the recommendations made at the Falls Screening and Education Event (mean $=8.66, S D$ $=1.91$, range $=1-10$ ). Please see Figure 1 for means and SD's on each of these variables.

The participants of this study also indicated that the Falls Screening and Educational Event, on average: (1) was valuable (mean $=4.33, S D=0.69$, range $=3-5) ;(2)$ enjoyable $($ mean $=4.52, S D=0.62$, range $=3-5) ;(3)$ understandable $($ mean $=4.70, S D=$ 0.47 , range $=4-5)$; and (4) that the interdisciplinary team members made them feel, on average, very comfortable $($ mean $=4.88$, $S D=0.33$, range $=4-5)$. Examining participants ratings by percentages, $85 \%$ of the participants found the Falls Screening and Educational Event to be either very or extremely valuable; a large majority (94\%) found the event to be either very or extremely enjoyable; all (100\%) found the event to be either very or extremely easy to understand; and all (100\%) indicated that the interdisciplinary team members made them feel very or extremely comfortable.

In terms of the qualitative comments, 31 of the 33 participants provided qualitative data. The participants expressed that they appreciated the: (1) comprehensiveness of the screenings and the fact that many different disciplines were involved $(n=15) ;(2)$ individual time with each discipline $(n=16)$; (3) individualized and client-centered recommendations $(n=26)$; (4) ability to stay in the same room and having the screeners rotate rooms $(n=2) ;(5)$ inclusion of things related to falls that they never thought about $(n=26)$; and (6) recommendations that could lead to healthier lifestyles and prevention of falls ( $n=23)$. The vast majority $(94 \%)$ of the participants did not recommend any suggestions for improvement; however, two participants recommended either providing

(c) The Internet Journal of Allied Health Sciences and Practice, 2022 
more snacks or adjusting the time of the event so that it is not close to the lunch hour. One participant recommended the inclusion of a video presentation. One participant suggested providing tests of walking. Suggestions for future event were primarily centered around topics related to overall health and wellness and including topics associated with nutrition, diet, and ability to prepare simple, yet healthy meals $(n=8)$, exercises and activities designed for older adults to improve strength, balance, and/or overall health $(n=6)$, issues related to aging (memory, osteoarthritis, care of aging parents) $(n=2)$, and sessions related to anxiety and depression $(n=1)$.

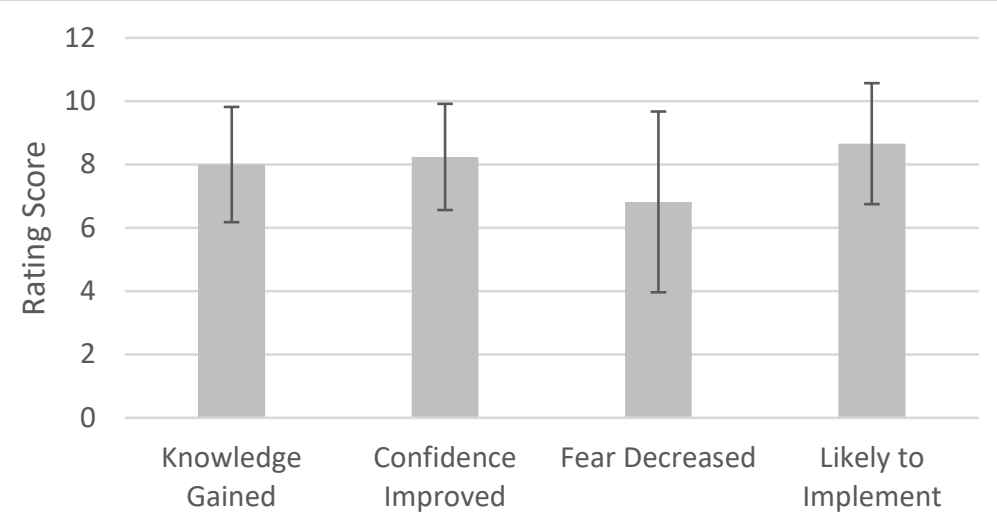

Knowledge Gained: "How much do you feel your knowledge of falls improved after attending the Falls Screening Event today?" Confidence Improved: "How much has your confidence improved in your own ability to prevent falls after attending the Falls Screening Event today?"

Fear Decreased: "How much has your fear of falling decreased after attending the Falls Screening Event today?" Implement: "How likely is it that you will implement the recommendations made at the Falls Screening Event today?"

Figure 1. Figure 1: Means (+/- $1 \mathrm{SD}$ ) of subjects' ratings from 0 (not at all) to 10 (completely) on perceived knowledge gained, confidence improved, fear decreased, and likelihood to implement recommendations for the falls screening event.

\section{DISCUSSION}

The purpose of this study was to determine the perceived value of an interdisciplinary falls screening and educational event for community-dwelling older adults. This event was conducted by licensed professionals from behavioral sciences, family medicine, occupational therapy, optometry, pharmacy, and physical therapy who screened participants using discipline-specific screening tools and offered individualized recommendations related to fall prevention to each participant. Thus, this screening event addressed the recommendations and guidelines established by the American Geriatrics Society/British Geriatrics Society, Centers for Disease Control and Prevention's Stopping Elderly Accidents, Deaths \& Injuries (STEADI), National Institute for Health and Care Excellence (NICE), and the United States Preventive Task Force (USPSTF), as it screened for fall risk in older adults by using multi-factorial assessments which were targeted at the evidence-based intrinsic and extrinsic risk factors and provided clientspecific suggestions to address identified risk factors. 3,6-7,11-15,21,40-41 More specifically, the interdisciplinary Falls Screening and Educational Event included screening for intrinsic risk factors such as history of a previous fall, functional limitations in balance and mobility, visual impairment, urinary incontinence, polypharmacy and/or benzodiazepine use, chronic disease such as cardiac and neurological disease, low body mass index, cognitive impairment, depression, anxiety, and impairments in activities of daily living, as well some of the major extrinsic risk factors such as improper use of assistive devices, and potential risks in the home such as unsafe steps, pavement, and flooring; lack of lighting; presence of obstacles, clutter, unsafe rugs, grab bars, railings; and placement of commonly used objects and methods to transport items in the house (e.g., laundry). Added benefits of hosting this type of event include potential cost-effectiveness for the providers and participants, as well as convenience factors (e.g., participants only need to schedule one appointment which may save time, money for transportation, etc.).

The results of this study suggest that events such as this Falls Screening and Education Event have the potential to: (1) increase knowledge regarding risks for falls and methods to prevent them; (2) improve confidence in ability to prevent falls; and (3) decrease fear of falling. Additionally, the feedback on the event itself indicated the event was received very positively in terms of value, enjoyment, ease of understanding of information, and comfort level with screeners. Qualitative feedback revealed the participants 
especially liked the comprehensiveness and the environmental set-up for this Falls Screening and Education Event. Participants also expressed appreciation for the client-centered recommendations to prevent falls and/or enhance performance in daily life. There were only a few suggestions for improvement; these were related to the timing of the event, the provision of more snacks, the inclusion of a video presentation, and providing tests of walking. Ideas for other events on health care and older adults indicated a desire for educational sessions on topics related to nutrition, exercise, activities designed for older adults to improve strength, balance, and/or overall health, anxiety/depression, and overall issues related to aging (e.g., memory, osteoarthritis, care of aging parents).

This study is consistent with data from studies examining emergency department or outpatient clinic screenings of older adults and is consistent with findings of perceived knowledge increase following educational events provided by a single allied healthcare discipline. For example, Barmentloo et al found that older patients from an emergency department or outpatient clinic had no negative expectations of fall risk screening and expected to benefit from such a screening. ${ }^{43}$ Likewise, Ott found that older participants who completed two educational sessions on falls increased falls risk knowledge and were likely to implement fall prevention techniques. ${ }^{43}$ Minimal time investment and low to no cost are often facilitators for fall risk screening. The screening process in this study was comprehensive and based on the current evidence and guidelines across disciplines. Comprehensive management of falls and fall risk factors are important due to the multi-factorial nature of falls. ${ }^{17}$

Since this study was conducted in a multidisciplinary healthcare clinic and there were limitations regarding availability of personnel as well as physical space, this study needed to restrict the maximum number of eligible participants to 50 community-dwelling older adults. However, even with these restrictions, the event did not reach its full capacity. It is possible that living distance from the clinic and/or lack of transportation impacted one's ability to attend this event. Since all participants in this study drove themselves or arranged for their own transportation, future events should consider potential transportation issues and perhaps offer the event in different locations and/or close to public transportation which may provide easier access. Since there were more participants in the first $(n=24)$ versus the second event $(n=9)$, recruitment strategies and/or timing of the event need to be considered in future studies. For example, even though the qualitative findings were overall extremely positive, two participants did comment on the timing of their lunch in relation to the screening process. Thus, perhaps future events could be scheduled further away from the lunch hour and/or include the provision of a meal. More importantly, due to the nature and purpose of this pilot study, it did not include a follow-up component. Future studies should consider the use follow-up procedures such as contacting the participants one month after the screening to assess and/or encourage follow through with multi-disciplinary recommendations and follow-up with their primary care provider and/or post-event surveys to assess for retainment of information and follow through with suggestions. Future studies could consider investigating and utilizing follow up tools that have been validated for use over the phone. Future screenings should also include a larger and more diverse sample size (e.g., socioeconomic status, ethnicity, nonindependent older adults, etc.). Since there is an increased risk of hearing loss in older adults which can play a role in fall risk, future events and studies should also consider the inclusion of an audiologist; unfortunately, this university did not have an audiology program nor did the multispecialty clinic have access to an audiologist on site.

Older persons who join fall prevention programming differ from those who do not join. For example, Calhoun et al found that socalled joiners and non-joiners shared similar values regarding loss associated with aging, independence, and emotional responses to falling ${ }^{44}$ However, they differed in their perceptions of need. Specifically, non-joiners were more likely to note they were either not at a critical point for intervention or beyond help and little could be done to prevent falling. Screenings clearly offer a participant insight into whether a participant is at risk and thus in need of a specific intervention. The participants' positive perceptions and engagement in this study is encouraging but the small sample highlights the need to reach more older adults, especially those who may be less likely to join or participate in these events. Screening is only the first step in the fall prevention process. Programming such as this should be linked with tangible, low-cost, and accessible intervention strategies with the appropriate follow-up. For example, participants could be referred to local educational seminars on health and wellness as well as local exercise classes (e.g., Tai Chi classes, classes aimed at improving strength and balance, etc.).

\section{CONCLUSION}

This study highlights the benefits of a collaborative and comprehensive interdisciplinary approach to falls screening on perceived knowledge and confidence in community dwelling adults. The results of this study support the value of interdisciplinary falls screening and educational events. Since each discipline made a unique contribution and included verbal and written recommendations, each community-dwelling older adult participant could share the detailed results and recommendations with their healthcare provider. The outcomes of this study appear to support the current evidence that comprehensive interdisciplinary falls screening events have the potential to be a positive first step in the fall prevention process for community-dwelling older adults.

(c) The Internet Journal of Allied Health Sciences and Practice, 2022 


\section{REFERENCES}

1. Burns ER, Stevens JA, Lee R. The direct costs of fatal and non-fatal falls among older adults - United States. J Safety Res. 2016;58:99-103. doi:10.1016/j.jsr.2016.05.001

2. Burns $E$, Kakara R. Deaths from falls among persons aged $\geq 65$ years - United States, 2007-2016. MMWR Morb Mortal Wkly Rep. 2018;67(18):509-514. doi:10.15585/mmwr.mm6718a1

3. STEADI - Older Adult Fall Prevention. Centers for Disease Control and Prevention. July 16, 2020. Accessed May 17, 2020. https://www.cdc.gov/steadi/about.html

4. Stevens, J. The Cost of Falls Among Older Adults. Centers for Disease Control and Prevention. 2013. Accessed May 18, 2015. http://www.cdc.gov/HomeandRecreationalSafety/Falls/fallcost.html.

5. Florence CS, Bergen G, Atherly A, Burns ER, Stevens JA, Drake C. Medical costs of fatal and nonfatal falls in older adults. J Am Geriatrics Society. 2018;66(4):693-698. doi:10.1111/jgs.15304

6. Lee R. The CDC's STEADI initiative: Promoting older adult health and independence through fall prevention. Am Fam Physician. 2017;96(4):220-221.

7. Byun M, Kim J, Kim M. Physical and psychological factors affecting falls in older patients with arthritis, Int J Environ Res Public Health. 2020;17(3):1098. doi:10.3390/ijerph17031098.

8. Eckert $\mathrm{T}$, Kampe $\mathrm{K}$, Kohler M, et al. Correlates of fear of falling and falls efficacy in geriatric patients recovering from hip/pelvic fracture. Clin Rehab. 2020;34(3):416-425. doi.org/10.1177/0269215519891233

9. Li Q, Mpofu E, Yin C, Turner KW. Perception of falls and confidence in self-management of falls among older adults. Int $J$ Environ Res Public Health. 2019;6(24):5054. doi:10.3390/ijerph16245054. PMID: 31835832; PMCID: PMC6950034.

10. Spano-Szekely L, Winkler A, Waters $C$, et al. Individualized fall prevention program in an acute care setting. Journal of Nursing Care Quality. 2019;34(2):127-132 doi: 10.1097/NCQ.0000000000000344

11. Cuevas-Trisan R. Balance problems and falls risks in the elderly. Clin Geriatr Med. 2019;35(2):173-183. doi:10.1016/j.cger.2019.01.008

12. Finucane $C$, Kenny RA. Falls risk, orthostatic hypotension, and optimum blood pressure management: Is it all in our heads? Am J Hypertens. 2017;30(2):115-117. doi:10.1093/ajh/hpw129

13. Manemann SM, Chamberlain AM, Boyd CM, et al. Fall risk and outcomes among patients hospitalized with cardiovascular disease in the community. Circ Cardiovasc Qual Outcomes. 2018;11(8):e004199. doi:10.1161/CIRCOUTCOMES.117.004199

14. Payette $M$, Belanger $C$, Leveille V, \& Grenier S. Fall-related psychological concerns and anxiety among community-dwelling older adults: Systematic review and meta-Analysis. PLOS One. 2016;11(4)_e0152848 DOI: 10.1371/journal.pone.0152848.

15. Watanabe JH. Medication use, falls, and fall-related worry in older adults in the United States. Consult Pharm. 2016;31(7):385-393. https://www.ncbi.nlm.nih.gov/pubmed/27412315 Home and recreational safety: Important facts about falls. Centers for Disease Control and Prevention. Updated February 10, 2017. Accessed May 17, 2020. https://www.cdc.gov/homeandrecreationalsafety/falls/adulffalls.html

16. Hopewell S, Copsey B, Nicolson P, Adedire B, Boniface G, Lamb S. Multifactorial interventions for preventing falls in older people living in the community: a systematic review and meta-analysis of 41 trials and almost 20,000 participants. $\mathrm{Br} \mathrm{J}$ Sports Med. 2020;54(22):1340-1350. doi:10.1136/bjsports-2019-100732

17. Falls in older people: assessing risk and prevention: Clinical guideline (CG161). National Institute for Health and Care Excellence (NICE). June 12, 2013. Updated: 23 May 2019. Accessed May 17, 2020. https://www.nice.org.uk/guidance/cg161

18. Final Recommendation Statement Falls Prevention in Community-Dwelling Older Adults: Interventions. United States Preventive Services Task Force (USPSTF). April 17, 2018. Accessed May 16, 2021. https://www.uspreventiveservicestaskforce.org/uspstf/document/RecommendationStatementFinal/falls-prevention-in-olderadults-interventions

19. Summary of the updated American Geriatrics Society/British Geriatrics Society clinical practice guideline for prevention of falls in older persons. J Am Geriatric Society. 2011;59(1)148-57. doi: 10.1111/j.1532-5415.2010.03234.x.

20. Laboni A, Flint AJ. The complex interplay of depression and falls in older adults: a clinical review. Am J Geriatr Psychiatry. 2013;21(5):484-492. doi:10.1016/j.jagp.2013.01.008

21. Folstein et al. Mini-mental state: A practical method for grading the cognitive state of patients for the clinician. $J$ Psychiatr Res. 1975;12(3):189-98.

22. Sheikh et al. Geriatric Depression Scale (GDS). Recent evidence and development of a shorter version. Clin Gerontol. 1986;5(1/2): 165-73.

23. Byrne GJ and Pachana NA. Development and validity of a short form of the Geriatric Anxiety Inventory - The GAI-SF. Int Psychogeriatr. 2001;23(1):125-31. 
24. Lin et al. A randomized, controlled trial of fall prevention programs and quality of life in older fallers. J Am Geriatr Soc. 2007;55(4):499-506.

25. Skelton, TC. What are the main risk factors for falls among older people and what are the most effective interventions to prevent falls? Copenhagen WHO Regional Office for Europe. 2004; Accessed June 1, 2015 http://www.euro.who.int/_data/assets/pdf_file/0018/74700/E82552.pdf

26. Act FAST. American Heart Association. 2021. https://www.stroke.org/understand-stroke/recognizing-stroke/act-fast/

27. Tomita MR, Saharan S, Rajendran S, Nochajski SM, Schweitzer JA. Psychometrics of the Home Safety Self-Assessment Tool (HSSAT) to prevent falls in community-dwelling older adults. Am J Occupational Therapy. 2014;68, 711-718. http://dx.doi.org/10.5014/ajot.2014.010801

28. Machiko RT. Home Safety Self-Assessment Tool (HSSAT) v.5. Department of Rehabilitation Science University at Buffalo, State University of New York. Accessed January 1, 2017. https://publichealth.buffalo.edu/content/sphhp/rehabilitationscience/research-and-facilities/funded-research/aging/home-safety-self-assessmenttool/_jcr_content/par/download_526197706/file.res/HSSAT-v.5-1-12-17.pdf

29. Horowitz BP, Almonte T, Vasil A. Use of the Home Safety Self-Assessment Tool (HSSAT) within Community Health Education to Improve Home Safety. Occup Ther Health Care. 2016;30(4):356-372. doi:10.1080/07380577.2016.1191695.

30. Pillay J, Freeman EE, Hodge W, et al. Screening for impaired visual acuity and vision-related functional limitations in adults 65 years and older in primary health care: Systematic review. Canadian Task Force on Preventive Health Care. November 2017. https://canadiantaskforce.ca/wp-content/uploads/2018/05/Systematic-Review_Screening-for-impaired-visual-acuityand-vision_Final_Nov-2017_v2-1.pdf

31. American Geriatrics Society 2015 Updated Beers Criteria for Potentially Inappropriate Medication Use in Older Adults. J Am Geriatr Soc. 2015;63(11):2227-2246. https://doi.org/10.1111/jgs.13702.

32. O'Mahony D, O'Sullivan D, Byrne S, O'Connor MN, Ryan C, Gallagher P. STOPP/START criteria for potentially inappropriate prescribing in older people: version 2 [published correction appears in Age Ageing. 2018 May 1;47(3):489]. Age Ageing. 2015;44(2):213-218.

33. National Center for Injury Prevention and Control, Division of Unintentional Injury Prevention. STopping Elderly Accidents, Deaths, and Injuries (STEADI) Tool Kit for Health Care Providers. Home and Recreational Safety: STEADI. Centers for Disease Control and Prevention. updated: April 11, 2013. Accessed September 3, 2013. http://www.cdc.gov/homeandrecreationalsafety/Falls/steadi/index.html

34. Rossiter-Fornoff JE, Wolf SL, Wolfson LI, Buchner DM. (1995) A cross-sectional validation study of the FICSIT common data base static balance measures. J Gerentol A Bio Sci Med Sci. 1995;50(6):M291-7.

35. Steffen TM, Hacker TA, Mollinger L. Age and gender-related test performance in community-dwelling elderly people: Sixminute walk test, berg balance scale, timed up \& go test, and gait speeds. Phys Ther. 2002;82(2):128-137.

36. Whitney SL, Wrisley DM, Marchetti GF, Gee MA, Redfern MS, Furman JM. Clinical measurement of sit-to-stand performance in people with balance disorders: validity of data for the five-times-sit-to-stand test. Phys Ther, 2005;85(10) 1034-1045.

37. Bradley C S, Rovner E, Morgan M et al. A new questionnaire for urinary incontinence diagnosis in women: development and testing. Am J of Obstet Gynecol 2005;192(1): 66-73.

38. Tinetti, M., D. Richman, et al. Falls efficacy as a measure of fear of falling. Journal of Gerontology. 1990;45(6): P239.

39. Keller RB and Slattum PW. Strategies for prevention of medication-related falls in the elderly. Consult Pharm. 2003;18(3): 248-258. https://www.ncbi.nlm.nih.gov/pubmed/16563058.

40. Muir SM, Gopaul K, Montero Odasso MM. The role of cognitive impairment in fall risk among older adults: A systematic review and meta-analysis. Age and Aging, 2012;41, 299-308.

41. Barmentloo LM, Dontje ML, Koopman MY, et al. Barriers and Facilitators for Screening Older Adults on Fall Risk in a Hospital Setting: Perspectives from Patients and Healthcare Professionals. Int J Environ Res Public Health. 2020;17(5):1461. doi:10.3390/ijerph17051461.

42. Creswell JW, Creswell JD. Research Design: Qualitative, Quantitative, and Mixed Methods Approaches. $5^{\text {th }}$ ed. Sage; 2018.

43. Ott, LD. The impact of implementing a fall prevention educational session for community-dwelling physical therapy patients Nursing Open. 2018;5:567-574.

44. Calhoun R, Meischke $\mathrm{H}$, Hammerback K, et al. Older adults' perceptions of clinical fall prevention programs: a qualitative study. J Aging Res. 2011;2011:867341. doi:10.4061/2011/867341 


\section{Appendix A}

Instructions: Please circle the number 1 (Not at all) through 10 (Completely) that best describes how you feel. There are no right or wrong answers. If you are unsure of which number to circle, just make your best guess.

How much do you feel your knowledge of falls improved after attending the Falls Screening Event today?

$\begin{array}{llllllllrr}1 & 2 & 3 & 4 & 5 & 6 & 7 & 8 & 9 & 10 \\ \begin{array}{l}\text { Not at } \\ \text { All }\end{array} & & & & & & & & & \text { Completely }\end{array}$

How much has your confidence improved in your own ability to prevent falls after attending the Falls Screening Event today?

\begin{tabular}{|cccccccccc}
1 & 2 & 3 & 4 & 5 & 6 & 7 & 8 & 9 & 10 \\
Not at All & & & & & & & & &
\end{tabular}

\begin{tabular}{|c|c|c|c|c|c|c|c|c|c|}
\hline $\begin{array}{c}1 \\
\text { Not at All }\end{array}$ & 2 & 3 & 4 & 5 & 6 & 7 & 8 & 9 & $\begin{array}{c}10 \\
\text { Completely }\end{array}$ \\
\hline
\end{tabular}

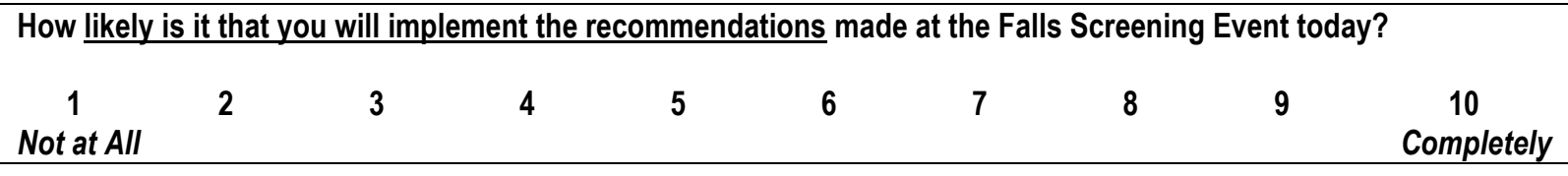




\section{Appendix B}

We would like your feedback on the event today. Please mark the response that best describes your current feelings. There are no right or wrong answers.

1. How valuable was the Falls Screening Event today?
$\square \quad$ Not at all
$\square$ Somewhat
$\square \quad$ Moderately
$\square$ Very
$\square \quad$ Extremely

2. How enjoyable was the Falls Screening Event today?
$\square \quad$ Not at all
$\square$ Somewhat
$\square \quad$ Moderately
$\square$ Very
$\square \quad$ Extremely

3. How easily understandable was the information presented at the Falls Screening Event today?
$\square \quad$ Not at all
口 Somewhat
口 Moderately
$\square$ Very
$\square \quad$ Extremely

4. How comfortable did the screeners make you feel at the Falls Screening Event today?
$\square \quad$ Not at all
$\square$ Somewhat
$\square \quad$ Moderately
$\square$ Very
$\square \quad$ Extremely

5. What did you like most about the Falls Screening Event today?

6. What suggestions do you have for improving the Falls Screening Event today?

7. What other events related to the health of older adults would you like offered? 